\title{
Assessment of the Refining Process Profitability for Biofuel Production - Rapeseed Pyrolytic Oil Case Study
}

\author{
Katarzyna Pstrowska*, Jerzy Walendziewski \\ Wroclaw University of Science and Technology, Faculty of Chemistry, Department of Fuels Chemistry \\ and Technology, Gdańska 7/9, 50-344 Wrocław, Poland
}

Received: 16 December 2020

Accepted: 10 February 2021

\begin{abstract}
On the basis of the ${ }^{1} \mathrm{H},{ }^{13} \mathrm{C}$ NMR and FT-IR spectroscopic results, elemental analysis and acid hydroxide group content analysis, the chemical structure of liquid fractions from pyrolysis of rapeseed treatment products was discussed. All the examined pyrolysis products contain a large number of unstable olefins as well as oxygen and nitrogen in aromatic rings or side hydrocarbon chains in aromatics. Although the liquid fractions obtained by pyrolysis of rapeseed and rapeseed processing products are potentially valuable fuel or fuel components, they need refining treatment. The best method, in this case, seems to be the hydrorefining process. It was shown that the hydrotreatment of such a complex composition requires incurring the costs of hydrogen for refining and construction costs of relevant installations or using existing ones in the nearest refinery. The costs of biofuel production from studied liquid pyrolysis products and other biomass-derived fractions should include the raw material costs as the logistics, i.e. transport of biomass and pyrolytic oils to the place of their pyrolysis or refining. In many cases, the costs of producing liquid fuels by biomass pyrolysis can be comparable or even higher than the value of the biofuel produced.
\end{abstract}

Keywords: pyrolysis, bioenergy, hydrorefining, upgrading, bio-oil

\section{Introduction}

Depleting of conventional, non-renewable stocks of energy, increasing costs of petroleum products and their negative influence on the environment lead to the intensification of alternative, renewable energy sources research. Biomass such as wood, timber wastes, agricultural wastes, and energy crops, take the

*e-mail: katarzyna.pstrowska@pwr.edu.pl an important role as a new energy source, providing currently about $11 \%$ of the total world's energy $[1,2]$.

The increase in total biomass use may improve the energy safety of the world. It could also diminish environmental pollution. Nowadays energy from biomass is obtained mainly by combustion or cocombustion of solid biofuels with fossil fuels. Another promising approach to biomass utilization is the thermochemical conversion of biomass: gasification, liquefaction, hydropyrolysis, and pyrolysis [1-4]. Pyrolysis of biomass allows its deep conversion and high yield (up to $70 \mathrm{wt}$ \%) of the pyrolysis oil characterized 
by the $\mathrm{H} / \mathrm{C}$ ratio above $1[5,6]$. Pyrolysis liquid product is a valuable material for further refining to obtain transportation fuels or heating fuel components.

In Poland, products of rapeseed (Brassica napus L.) processing (i.e. seeds, oil cake and oil meal), can be favourable raw materials for obtaining of bio-oils by thermochemical conversion of biomass. The predominant amount of rapeseed waste is obtained as a by-product of rapeseed oil production by the press (rapeseed cake) and extraction (rapeseed meal) methods.

The concept of the bio-oil obtaining from rapeseed processing by-products is currently supported by the increase in demand for biodiesel (FAME) production. A significant increase in FAME production was observed in recent years, from 414 million liters in 2011 up to the value of 1000 million liters production in 2019 in Poland [7]. Despite the plans to utilize a substantial part of the produced rapeseed cake and rapeseed meal as high-quality fodder, there should be a sufficient amount of oil processing by-product plants to meet the demand for raw materials for bio-oil production.

Yield and properties of pyrolytic oil depend on various factors such as biomass type, process implementation parameters (fixed or fluidized bed), process temperature, heating rate, the residence time of the products in the reaction zone, inert atmosphere $[3,8,9]$. The knowledge of the pyrolytic oils chemical structure and thermal decomposition kinetics is crucial to optimize conditions of further hydrorefining process. The chemical composition of bio-oils is often studied by spectroscopic methods. Spectroscopic techniques like FT-IR spectroscopy can give insights into the functional groups present in the bio-oils, but only in a qualitative measure. Few studies have used ${ }^{1} \mathrm{H}$ and ${ }^{13} \mathrm{C}$ NMR to obtain approximate ratios of the chemical environments of protons and carbon atoms and determined the approximate aromatic/aliphatic ratio $[10,11]$. There are few studies on the chemical composition of biooil extracted phases (e.g. n-pentane soluble, n-pentane insoluble) [10]. According to the authors' knowledge, the ${ }^{13} \mathrm{C}$ NMR technique was applied to a wide range of bio-oil types, but not for rapeseed or rapeseed waste bio-oils.

Several articles have mentioned liquid fractions obtained from biomass pyrolysis being the potential raw materials for liquid fuel production [2, 12]. Various methods of refining them are proposed, among others by catalytic cracking and hydrodeoxygenation [1315]. The problem is that in the case of catalytic cracking processes, the proposed catalysts facilitate decarboxylation and removal of oxygen in the form of $\mathrm{CO}_{2}$ but are deactivated and require continuous regeneration by oxidative removal of coke [16-18]. They also do not provide liquid fuels of the right quality because deep hydrotreatment requires severe process conditions and this in turn causes partial cracking. As a result, it is difficult to completely remove heteroatoms as nitrogen and sulphur. Emulsification of pyrolysis oils with diesel fuels also gives moderate effects [19-21]. In this case, good quality diesel or heating fuel is contaminated with pyrolysis oil components. Proposals for the production of synthesis gas from oil and the use of gas for the synthesis of Fischer Tropsch seem to be completely irrational [12]. Another suggestion is the pyrolysis of biomass and hydrotreating of pyrolysis oil using hydrogen from the conversion of natural gas with steam [12]. In that case, biomass processing requires three installations, pyrolysis, hydrogen production in the methane-steam conversion process, and hydrotreating. In another publication, the authors state in their conclusions that biomass such as rapeseed oil cake, an agricultural residue resulting from the extraction of oil from rapeseeds, can become a suitable candidate for liquid fuel production and can reduce the fossil fuel consumption [10, 22]. Similarly, in other publications, the authors state that bio-oil from biomass pyrolysis, e.g. rapeseed cake, can be a raw material for the production of biofuels after upgrading processes [10, 22, 23].

Fuel application of pyrolytic bio-oil is presented in numerous publications (e.g. $[9,23]$ ) although the liquid product of the biomass pyrolysis process contains organic compounds of sulphur, nitrogen, and oxygen as well as unsaturated hydrocarbons. These compounds in bio-oil require hydrotreatment and consumption of large amounts of hydrogen for this purpose. The process of biomass pyrolysis also requires the consumption of large amounts of energy as it is carried out at a temperature of ca. $500{ }^{\circ} \mathrm{C}$ and the pyrolysis product requires drying before hydrotreatment. Despite serve process conditions, the liquid products obtained as a result of hydrotreating from the oil cake pyrolysis process were not satisfactory. Thus, this study attempts to assess the purposefulness of the production of liquid fuel components from biomass waste such as oil cake by pyrolysis and hydrotreatment of the bio-oil produced by this method. It seems more rational to use biomass such as oil cake in other biotechnological processes [24, 25].

The analytical studies of liquid products obtained from rapeseed, its meal and cake pyrolysis provided the detailed chemical composition of the tested bio-oils. Special emphasis was put on elemental analysis and precise ${ }^{13} \mathrm{C}$ NMR spectra analysis. This study is useful for optimizing the hydrorefining process to produce liquid fuel components used as heating oil or engine fuel. Based on the current costs of hydrogen production, an assessment of the energy costs of hydrotreatment of bio-oils was also made.

\section{Experimental}

\section{Materials}

The rapeseed grain (Brassica napus L.), rapeseed cake, and meal investigated in this study were taken 
from a company located in Lower Silesia, west-south region of Poland.

\section{Pyrolysis of Raw Materials and Hydrorefining of Pyrolytic Oils}

Pyrolysis experiments were carried out at a temperature of $500^{\circ} \mathrm{C}$. The pyrolysis setup is presented in Fig. 1. The applied pyrolysis reactor was a fixed bed design and made of quartz with a $65 \mathrm{~mm}$ diameter and $130 \mathrm{~mm}$ height. The reactor was heated externally by an electrical furnace in which temperature was measured with two thermocouples $\mathrm{K}$ type (NiCr-NiAl). One thermocouple was placed in the center of the reactor, the second one in the wall of the furnace (space between the furnace and the reactor). Before the experiments, the glass reactor was purged with argon for $15 \mathrm{~min}$ at a flow rate of $20 \mathrm{l} / \mathrm{h}$ to remove air. In the typical experiment, $100 \mathrm{~g}$ of the rapeseed material was loaded to the reactor and then, the reactor temperature was increased with a heating rate of $5^{\circ} \mathrm{C} / \mathrm{min}$ up to final desirable temperature and hold for $30 \mathrm{~min}$ in that temperature to complete the process. The gaseous pyrolysis products were flowing through a water condenser, where were condensed and cooled in a water jacket and next in a cold trap maintained at $-5^{\circ} \mathrm{C}$. The liquid products were separated into aqueous and oil fractions. Bio-oils were additionally dried over anhydrous sodium sulfate and filtered. The hermetically closed glass bottles with oils were stored at reduced temperature. For each raw material, pyrolysis was conducted in triplicate to verify the reproducibility of the results obtained. Observed differences in the yield of the products were not higher than $5 \%$.

Hydrorefining procedure was described in our previous paper [26].

\section{Raw Materials and Bio-Oil Characterization}

Proximate analysis, volatile matter and an ash content of raw materials were determined according to ASTM D 3174-89 and ASTM D 3175-89a respectively. Raw material oil content was determined with polish

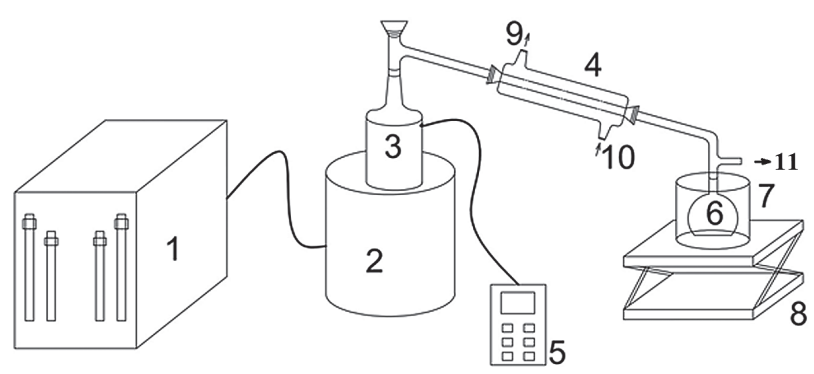

Fig. 1. Pyrolysis setup: 1 - temperature controller, 2-electrical furnace, 3- quartz reactor, 4- water flow cooler, 5- digital thermometer, 6- round bottom flask in ice bath, 7-beaker, 8-manual lift, 9-water inlet, 10-water outlet, 11- to tank and gas measurement. standard PN-EN ISO 734-1, moisture content according to ASTM D6304-7. Elemental analysis of raw materials and obtained bio-oils was carried out using a CHNS EA $1110 \mathrm{CE}$ Instruments analyser. The sulphur content was measured using a Varian - ICP-AES Liberty 220 analyser, the oxygen content was calculated from difference.

FT-IR spectra of the bio-oils were recorded with a Vector 22 Bruker. Analysis of bio-oil was carried out on thin films between $\mathrm{KBr}$ plates. The NMR Bruker DRX 300 spectrometer with a $5 \mathrm{~mm}$ broadband probe was used to record the ${ }^{1} \mathrm{H}$ NMR and ${ }^{13} \mathrm{C}$ NMR. The ${ }^{1} \mathrm{H}$ NMR spectra of the oils $(200 \mu \mathrm{l}$ of bio-oils were mixed with $300 \mu \mathrm{CDCl}_{3}$ ) was obtained at $\mathrm{H}$ frequency of $300.12 \mathrm{MHz}$, measured in the range $-3.838-16.137 \mathrm{ppm}$, pulse program zg 30, acquisition time $5.46 \mathrm{~s}$ with 16 scans. The ${ }^{13} \mathrm{C}$ spectra, at $\mathrm{C}$ frequency of $75.45 \mathrm{MHz}$, was measured in the range $-10-230 \mathrm{ppm}$, pulse program: zgig (inverse gated decoupling with 90-degree flip angle), acquisition time 3.62s, delay: 30s, 1024 scans. The percentage of protons and carbon atoms in different groups was determined according to the method proposed by Mullen and co-workers [10] using spectra of equimolar solution (1:1:1:1) of 1-hexene, isooctane, $\mathrm{m}$-cresol, and 4-methyl-2-pentanone. Differences in relaxation time of the obtained spectra were corrected using the standard mixture correlations.

Acid hydroxide groups' content in w bio-oils was determined by the thermometric titration method in the presence of acetone [27]. Additionally, the bio-oils bromine number was determined according to ASTM D 1491-60.

\section{Results and Discussion}

\section{Characteristic of Raw Materials and Bio-Oils}

The characteristics of the rapeseed raw materials used in this study are presented in Table 1. Results of elemental analysis of the obtained pyrolytic oils, their bromine number, and content of acid hydroxide groups are presented in Table 2.

The obtained results indicate essential differences between properties of initial raw materials (i.e. rapeseed, rapeseed meal, and rapeseed cake): their volatile matter content, elemental composition, $\mathrm{H} / \mathrm{C}$ and $\mathrm{O} / \mathrm{C}$ atomic ratio and oil content (Table 1). The above mentioned raw materials are characterized by similar bulk density (about $0.5 \mathrm{~g} / \mathrm{cm}^{3}$ ) and ash content (about $6 \mathrm{wt} \%$ daf). The only exception is rapeseed with $3.6 \mathrm{wt}$. \% daf ash content. The content of volatile matter range from 90.2 wt. \% daf for rapeseed to 72.7 wt. \% daf for rapeseed meal. There are also differences in oil content which is the highest (40.3 wt. \% daf) for rapeseed and the lowest one ( 4.3 wt. \% daf) for rapeseed meal. The results of elemental analysis (Table 1) show a relatively high concentration of hydrogen in the initial raw materials, from 10.1 to 7.9 wt. \% daf correspondingly 
Table 1. Raw materials characteristic.

\begin{tabular}{|c|c|c|c|}
\hline Characteristics & Rapeseed & Rapeseed cake & Rapeseed meal \\
\hline \multicolumn{4}{|c|}{ Elemental analysis [wt \%, daf] } \\
\hline $\mathrm{C}$ & 64.81 & 52.94 & 54.66 \\
\hline $\mathrm{H}$ & 10.08 & 7.88 & 8.88 \\
\hline $\mathrm{N}$ & 3.24 & 6.67 & 7.69 \\
\hline $\mathrm{S}$ & 0.32 & 0.57 & 0.01 \\
\hline $\mathrm{O}^{\mathrm{a}}$ & 21.55 & 31.94 & 28.76 \\
\hline Moisture content, [wt. \%] & 6.0 & 5.0 & 10.4 \\
\hline Oil content, [wt. \%, daf] & 40.3 & 14.3 & 4.3 \\
\hline Atomic $\mathrm{H} / \mathrm{C}$ ratio & 1.87 & 1.79 & 1.95 \\
\hline Atomic $\mathrm{O} / \mathrm{C}$ ratio & 0.25 & 0.45 & 0.39 \\
\hline Empirical formula & $\mathrm{CH}_{1,87} \mathrm{O}_{0,25} \mathrm{~N}_{0,04} \mathrm{~S}_{0,002}$ & $\mathrm{CH}_{1,79} \mathrm{O}_{0,45} \mathrm{~N}_{0,11} \mathrm{~S}_{0,004}$ & $\mathrm{CH}_{1,95} \mathrm{O}_{0,39} \mathrm{~N}_{0,12} \mathrm{~S}_{0,00007}$ \\
\hline
\end{tabular}

a - calculated by the difference

for rapeseed and rapeseed cake. The contents of nitrogen range from $3.2 \mathrm{wt}$. \% daf for rapeseed to 7.7 wt. \% daf for rapeseed meal. The initial raw materials are also characterized by high oxygen content (21.6-31.9 wt. \% daf) and a rather small content of sulphur (below 0.6 wt. \% daf). The $\mathrm{H} / \mathrm{C}$ atomic ratio for all materials is similar and amounts to about 1.9.

Due to the diverse raw material properties, biooils vary in their yield and properties. Bio-oil yields originated from thermal decomposition of rapeseed, rapeseed cake and rapeseed meal at $500^{\circ} \mathrm{C}$ are 44.4 , 25.9, and $17.1 \mathrm{wt}$. \%, respectively. All the liquid products are characterized by a high bromine number (from $59.4 \mathrm{~g} \mathrm{Br}_{2} / 100 \mathrm{~g}$ for rapeseed to $104.2 \mathrm{Br}_{2} / 100 \mathrm{~g}$ for rapeseed meal used as the raw material). Similarly, initial raw materials, bio-oils are characterized by relatively high hydrogen content (8.8-11.7 wt. \% daf) and nitrogen content (2.9-8.2 wt. \%) especially in the case of oils from rapeseed cake and meal. In comparison to the raw materials oxygen content in obtained bio-oils is considerably lower and ranges from 4.7 to $10.5 \mathrm{wt}$ \%. This indicates that during the pyrolysis process elimination of oxygen from feedstock is much more privileged than the elimination of nitrogen. Nevertheless, a relatively high concentration of nitrogen and oxygen in obtained bio-oils might have a negative impact on hydrorefining process efficiency.

Table 2. Pyrolytic oils properties.

\begin{tabular}{|c|c|c|c|}
\hline \multirow{2}{*}{ Characteristic } & \multicolumn{3}{|c|}{ The raw material for the pyrolysis process } \\
\hline & Rapeseed & Rapeseed cake & Rapeseed meal \\
\hline \multicolumn{4}{|c|}{ Elemental analysis [wt \%, daf.] } \\
\hline $\mathrm{C}$ & 80.50 & 71.50 & 72.50 \\
\hline $\mathrm{H}$ & 11.71 & 10.20 & 8.82 \\
\hline $\mathrm{N}$ & 2.87 & 7.05 & 8.25 \\
\hline $\mathrm{S}$ & 0.18 & 0.70 & 0.08 \\
\hline $\mathrm{O}^{\mathrm{a}}$ & 4.74 & 10.55 & 10.35 \\
\hline Acid $\mathrm{OH}$ content [wt. \%] & 2.10 & 4.15 & 4.77 \\
\hline Atomic $\mathrm{H} / \mathrm{C}$ ratio & 1.74 & 1.71 & 1.46 \\
\hline Atomic $\mathrm{O} / \mathrm{C}$ ratio & 0.04 & 0.11 & 0.11 \\
\hline Empirical formula & $\mathrm{CH}_{1,74} \mathrm{O}_{0,04} \mathrm{~N}_{0,03} \mathrm{~S}_{0,0008}$ & $\mathrm{CH}_{1,74} \mathrm{O}_{0,15} \mathrm{~N}_{0,09} \mathrm{~S}_{0,004}$ & $\mathrm{CH}_{1,46} \mathrm{O}_{0,11} \mathrm{~N}_{0,10} \mathrm{~S}_{0,0004}$ \\
\hline Bromine number $\left[\mathrm{g} \mathrm{Br}_{2} / 100 \mathrm{~g}\right]$ & 59.4 & 79.7 & 104.2 \\
\hline
\end{tabular}

a - calculated by the difference 


\section{Chemical Structure of Bio-Oils}

Fig. 2 shows the infrared spectra, representing the functional group composition of the pyrolytic biooils. The $\mathrm{C}-\mathrm{H}$ stretching vibrations between 3000 and $2840 \mathrm{~cm}^{-1}$, stretching vibration $-\mathrm{C}-\mathrm{C}$ - between $1200-800 \mathrm{~cm}^{-1}$ and vibrations from methylene groups $-\mathrm{CH}_{3}$ at 2762 and $2872 \mathrm{~cm}^{-1}$ frequency are typical for the presence of alkane groups and were found in all analyzed spectra. It is worth noticing that all spectra include a peak in the vicinity of the $720 \mathrm{~cm}^{-1}$ frequency which indicates the presence of $>\mathrm{C}_{7}$ branched alkanes. This indicates the pyrolysis process in $500^{\circ} \mathrm{C}$ leads to light products, mainly alkanes. Alkene $\mathrm{C}=\mathrm{C}$ stretching vibrations is visible between 1667 and $1640 \mathrm{~cm}^{-1}$ while aromatic hydrocarbons bands between 900-675 and 1420-1610 $\mathrm{cm}^{-1}$. Oxygen-containing groups are represented by alcohols (vibration in the range of 3700-3584 and 3550-3200 $\mathrm{cm}^{-1}$ ), phenols (12601000 and 1260-1180 $\mathrm{cm}^{-1}, 3000-3400 \mathrm{~cm}^{-1}$ ), ketones (strong band between 1700-1750 $\mathrm{cm}^{-1}$ ), aldehyde groups $\left(1740-1720 \mathrm{~cm}^{-1}\right)$ and carboxylic acids $\left(3300-2500 \mathrm{~cm}^{-1}\right.$ and $\left.1320-1210 \mathrm{~cm}^{-1}\right)$. In the case of the bio-oil from rapeseed grain, the found oxygen groups were ketones and alcohols. While the rapeseed oil cake and oil meal containing all the mentioned oxygen-containing groups. Weak, single vibrations about 3500 and $3400 \mathrm{~cm}^{-1}$ and middle to strong bands between $1650-1580 \mathrm{~cm}^{-1}$ indicate the presence of primary amines. The presence of these functional groups was observed in all examined bio-oils. It is impossible to determine the content of secondary amines in such mixture because the bands typical for that group appear between $3350-3310 \mathrm{~cm}^{-1}$ (frequency range of alcohols and phenols presence) [28]. The obtained results correlate well with published so far results describing pyrolytic oils (e.g. rapeseed [29], rapeseed oil cake [22]).

The integral values of selected regions of the ${ }^{1} \mathrm{H}$ NMR spectra on a percentage basis are presented in Table 3. It is evident that the major differences in the overall chemical composition of the bio-oils result from the different feedstocks. The most characteristic region of the spectra, from 0.5 to $1.5 \mathrm{ppm}$, represents aliphatic protons. In the case of the bio-oils from rapeseed, the supreme content of aliphatic protons was observed in bio-oil from rapeseed (64.4\%), successively lower from rapeseed cake (45.9\%) and bio-oil from rapeseed meal $(36.0 \%)$. The next integrated region was calculated from 1.5 to $3.0 \mathrm{ppm}$. This region represents protons in aliphatic carbon atoms that may be bonded to $\alpha \mathrm{C}=\mathrm{C}$ double bond (aromatic or olefin) or are placed at two bonds away from a heteroatom. The content of those protons $(\sim 27 \%)$ is relatively high for all analysed products. Referring to Mullen et.al. [10] in that spectra region, it is also possible to observe water present in bio-oils. In the case of the analysed products, measured water content was below 1 wt. \%, which in our opinion should not influence spectra image. The next integrated region 3.0-4.4 ppm contained $4.9 \%$ of the protons in bio-oil from rapeseed meal and $0.4 \%$ of the protons in bio-oil from rapeseed. The described spectra region corresponds to alcohol, ethers, or a methylene group that joins two aromatic rings. Such complex molecules as methylene groups that join two aromatic rings, may

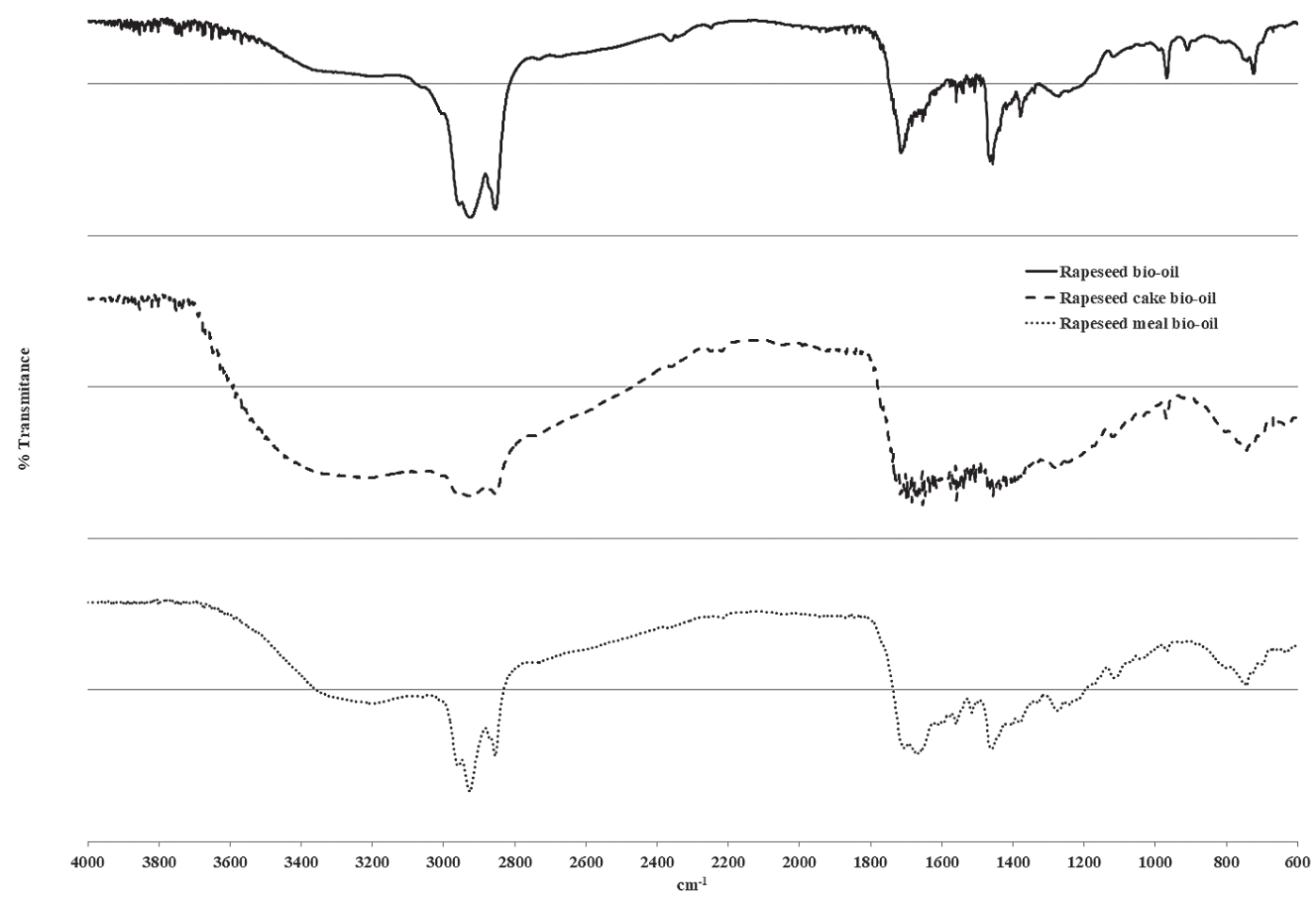

Fig. 2. Bio-oils infrared spectra. 
Table 3. Percentage composition of hydrogen-based on ${ }^{1} \mathrm{H}$ NMR analysis of bio-oils from slow pyrolysis of rapeseed grain, rapeseed oil cake, and rapeseed oil meal.

\begin{tabular}{|c|c|c|c|c|}
\hline \multirow{2}{*}{$\begin{array}{c}\text { Chemical shifts } \\
{[\mathrm{ppm}]}\end{array}$} & \multirow{2}{*}{ Proton assignment } & \multicolumn{3}{|c|}{ Pyrolysis oil made using: } \\
\hline & & Rapeseed \% & Rapeseed cake \% & Rapeseed meal \% \\
\hline $0.5-1.5$ & Alkanes & 64.4 & 45.9 & 36.0 \\
\hline $1.5-3.0$ & Aliphatics- $\alpha$ to olefins or heteroatom & 25.8 & 27.1 & 29.4 \\
\hline $3.0-4.4$ & Alcohols, a methylene bridge, ethers & 0.4 & 3.3 & 4.9 \\
\hline 4.4-6.0 & Methoxy, carbohydrate derivatives & 3.6 & 6.4 & 4.1 \\
\hline $6.0-8.5$ & (hetero-) aromatics & 5.8 & 17.3 & 24.8 \\
\hline $9.5-10.0$ & Aldehydes, carboxylic acids & - & - & 0.8 \\
\hline
\end{tabular}

exist in case of the incomplete decomposition of lignin. In the case of bio-oil from rapeseed meal, the least oil content in the raw material (Table 1) corresponds to the presence of an enlarged amount of more complex molecules as lignin or hemicellulose. The region between 4.4 and $6.0 \mathrm{ppm}$ represents aromatic ether protons, lignin-derived methoxyphenols, and other hydrogen atoms of carbohydrate-like molecules [12]. The presence of aromatic ethers is a result of incomplete lignin decomposition and transformations. The content of aromatic ether protons in analyzed bio-oils varies between 3.6-6.4\%. Complex (hetero-) aromatic protons (aromatics containing $\mathrm{O}$ and $\mathrm{N}$ elements) were measured in the range 6-8.5 ppm. Aldehyde and the carboxylic acid group were observed only in bio-oil from rapeseed meal (9.50.0 ppm, 0.8\%).

${ }^{13} \mathrm{C}$ NMR spectra calculations are presented in Table 4. A decrease in oil content in the pyrolysis raw material results in increased content of large, more chemically complex components in biooils. Aliphatic carbon content in the bio-oil from rapeseed was calculated as $74 \%$, while in the biooil from rapeseed cake quantity of aliphatic carbon was calculated as $69.8 \%$ (Table 4 ). The total content of aromatic and olefin carbon atoms varies between $24.2 \%$ (bio-oil from rapeseed) and $54.7 \%$ (biooil from rapeseed meal). An increase in unsaturated compounds content in the bio-oils structure was confirmed by bromine number determination (Table 2), which increases with the decrease of oil content in the raw material applied in the pyrolysis process. The determined total aromatics and olefins content in bio-oil from rapeseed using ${ }^{13} \mathrm{C} \mathrm{NMR}$ spectroscopy was $24.2 \%$, while bromine number was $59.4 \mathrm{gBr}_{2} / 100 \mathrm{~g}$. On the other hand, the determined total aromatics and olefins content in bio-oil from rapeseed meal using ${ }^{13} \mathrm{C}$ NMR spectroscopy was $54.7 \%$ and bromine number was $104.2 \mathrm{gBr}_{2} / 100 \mathrm{~g}$. Alcohol, ether, and carbohydrate group peaks were not observed in the analyzed spectra (chemical shift $55-95 \mathrm{ppm}$ ). ${ }^{13} \mathrm{C}$ NMR analysis calculations were confirmed by the increase of acid hydroxide group content (Table 2), which indicates an increase of phenols content. Carbon atom peaks derived from esters and carboxylic acids were observed only in the case of bio-oil from rapeseed meal $(1.6 \%)$. The results of bio-oils elemental analysis (Table 2), ${ }^{1} \mathrm{H} \mathrm{NMR}$, and ${ }^{13} \mathrm{C} \mathrm{NMR}$ spectra analysis indicate that oxygen and nitrogen molecules are bonded

Table 4. Results of calculation of percentage content of carbon-based on 13C NMR analysis of the pyrolytic bio-oils.

\begin{tabular}{|c|c|c|c|c|}
\hline \multirow{2}{*}{$\begin{array}{c}\text { Chemical shift } \\
{[\mathrm{ppm}]}\end{array}$} & Carbon assignments & \multicolumn{3}{|c|}{ Pyrolysis oil made using: } \\
\cline { 3 - 5 } & & Rapeseed $\%$ & Rapeseed cake $\%$ & Rapeseed meal \% \\
\hline $0-55$ & Aliphatics, Total & $\mathbf{7 4 . 0}$ & $\mathbf{6 9 . 8}$ & $\mathbf{4 2 . 9}$ \\
\hline $0-15$ & peripheral $\mathrm{CH}_{3}$-olefins & 10.6 & 11.5 & 5.1 \\
\hline $15-20$ & peripheral, $\mathrm{CH}_{3}$-aliphatics & 4.0 & 5.2 & 6.7 \\
\hline $20-30$ & Inside chain $-\mathrm{CH}_{2}$ & 34.3 & 40.5 & 17.5 \\
\hline $30-55$ & Chain branching $-\mathrm{CH}_{2}$ & 25.1 & 12.6 & 13.6 \\
\hline $55-95$ & Alcohols, ethers, carbohydrates & 0.0 & 0.0 & 0.0 \\
\hline $95-165$ & Aromatics, olefins, Total & $\mathbf{2 4 . 2}$ & $\mathbf{2 9 . 1}$ & $\mathbf{5 4 . 7}$ \\
\hline $165-180$ & Esters, carboxylic acids & 0.0 & 0.0 & $\mathbf{1 . 1}$ \\
\hline $180-215$ & Ketones, aldehydes, Total & $\mathbf{1 . 4}$ & $\mathbf{0 . 8}$ \\
\hline
\end{tabular}


in aromatic rings or side hydrocarbon chains in aromatic compounds.

\section{Evaluation of Hydrogen Consumption in the Hydrorefining Process of Pyrolysis Bio-Oils From Rapeseed Cake Pyrolysis}

Bio-oils, or more precisely fractions of liquid hydrocarbons from pyrolysis of rapeseed, are products with a very complex structure and composition. They contain large amounts of organic nitrogen, oxygen, and relatively small amounts of sulphur. Pyrolytic oils also contain a large number of unsaturated hydrocarbons. As a result, these products are very unstable, and during their storage resin deposits form quite quickly. Due to the high content of nitrogen during the combustion of such fuel, nitrogen oxides may be formed, and due to the high content of oxygen derivatives, the calorific value of the fuels obtained is lower.

There are various proposals regarding the energetic use of bio-oils from pyrolysis, including the production of hydrogen in the conversion process with steam [30]. In catalytic conversion processes, e.g. nickel catalysts are exposed to poisoning with sulphur compounds as well as to rapid deactivation by unstable olefin hydrocarbons and organic hetero-compounds in oil. Their use as heating or engine fuel requires a refining process soon after their production. Currently, it is not possible to use chemical methods for this purpose, such as acid and lye methods, therefore the only rational refining method is hydrotreatment, i.e. a catalytic process using hydrogen. In this process, it is necessary to hydrogenate unsaturated hydrocarbons, hydrogenate organic sulphur, nitrogen, and oxygen compounds. Each of these reactions requires the use of hydrogen. In the following statement, we have calculated the amount of hydrogen needed for full refining, i.e. total hydrogenation of olefins to the appropriate paraffin hydrocarbons and total hydrogenolysis of sulphur, nitrogen and oxygen hetero compounds also to the appropriate kinds of paraffin, as well as hydrogen sulfide, ammonia and water.

Bio-oil from the pyrolysis of rapeseed cake from the production of rapeseed oil by the extrusion method was used for the calculations. Rapeseed cake is one of the most important products of the rapeseed oil production process for the production of FAME biofuels. According to the data in Table $2,1 \mathrm{~kg}$ of the pyrolytic oil contains, taking into account the elemental composition and transforming it, respectively, into $\mathrm{g}$ atom:

$105.5 \mathrm{~g}$ of oxygen, i.e. $105.5 / 16$ of oxygen $\mathrm{g}$ atoms $=6.6 \mathrm{~g}$ oxygen $\mathrm{g}$ atoms,

$70.5 \mathrm{~g}$ of nitrogen, i.e. $70.5 / 14 \mathrm{~g}$ of nitrogen $\mathrm{g}$ atoms $=5.04$ nitrogen $\mathrm{g}$ atoms,

$7 \mathrm{~g}$ of sulphur, i.e. 7/32 sulphur $\mathrm{g}$ atoms $=0.22$ sulphur $\mathrm{g}$ atoms.

The theoretical consumption of hydrogen in the hydrotreatment process is easiest calculated based on reaction patterns occurring in the hydrogenolysis process of the selected organic compounds of oxygen, nitrogen and sulphur in the presence of CoMo or NiMo hydrotreating sulfide catalysts used in hydrotreating processes of products of petroleum or coal origin (e.g. from coking processes).

\section{Hydrogenolysis of Oxygen Derivatives}

- Hydrogenation of hydroxyl groups, hydrogen consumption of 1 mole per gram of oxygen;

- Hydrogenation of ether bonds, hydrogen consumption of 2 moles of oxygen gram;

- Hydrogenation of phenols, hydrogenolysis of oxygen binding and hydrogenation of the heterocyclic ring: hydrogen consumption of 3 moles per $\mathrm{g}$ mol of oxygen;

- Hydrogenolysis of carboxyl groups: 3,5 $\mathrm{H}_{2}$ moles per 1 carboxyl groups, $1.75 \mathrm{H}_{2}$ moles per $\mathrm{g}$ mol of oxygen.

Assuming that oxygen is present in the form of hydroxyl groups of alcohols, ethers or phenols and heterocyclic compounds such as condensed furans, the average hydrogen consumption is 2.5 moles of hydrogen per oxygen $\mathrm{g}$ atoms. In the hydrogenolysis, the reaction of oxygen compounds in $1 \mathrm{~kg}$ of oil from the pyrolysis oil cake containing 6.6 oxygen $\mathrm{g}$ atoms is 6.6 x 2.5 moles of hydrogen $=16.5$ mole or $369.6 \mathrm{dm}^{3}$ of hydrogen.

\section{Hydrogenolysis of Nitrogen-Containing Compounds}

The product of hydrogenolysis of amine derivatives similar in structure to pyridine is ammonia and pentane, or pentane substituted for other molecules, hydrogen consumption of 5 moles per 1 gram of nitrogen. Assuming that nitrogen is present in the pyrolytic oils in the form of heterocyclic nitrogen derivatives such as pyridine, the average hydrogen consumption is 4.5 moles of hydrogen per 1 species of nitrogen. The hydrogenolysis reaction of nitrogen compounds in pyrolysis oil containing 5.04 nitrogen species consumes $5.04 \times 4.5$ moles of hydrogen $=22.68$ moles hydrogen or $508 \mathrm{dm}^{3}$ hydrogen.

\section{Hydrogenolysis of Sulphur-Containing Compounds}

The product of mercaptans hydrogenolysis is hydrocarbons and hydrogen sulfide (hydrogen consumption $1 \mathrm{~mol}$ ). The product of benzothiophene hydrogenolysis is hydrogen sulfide and ethylbenzene, which results in hydrogen consumption 6 moles. Assuming that the sulphur is in the form of mercaptans and heterocyclic sulphur derivatives such as thiophene or benzothiophene, the average hydrogen consumption is 3.5 moles of hydrogen per $1 \mathrm{~g}$ atom of sulphur. Thus, in the hydrogenolysis reaction of sulphur compounds, 0.22 sulphur $\mathrm{g}$ atom in $1 \mathrm{~kg}$ of oil, $0.22 \times 3.5 \mathrm{~mol}$ hydrogen/sulphur species $=0.77 \mathrm{~mol}$ hydrogen or $17.25 \mathrm{dm}^{3}$ hydrogen is consumed. 


\section{Hydrogenation of Unsaturated Hydrocarbons (Olefins)}

The olefin bond's presence in fuels is characterized by the bromine number determination. It has been assumed that the bromine number of oil from oil cake is on average $70 \mathrm{~g} \mathrm{Br}_{2} / 100 \mathrm{~g}$, which concerning $1 \mathrm{~kg}$ of weight of 1 oil gives the consumption of bromine attached to the double bonds $700 \mathrm{~g} \mathrm{Br}_{2} / 1 \mathrm{~kg}$, i.e. 4.38 mole of bromine. The same amount of hydrogen can be attached to olefins when they are completely hydrogenated, i.e. 4.38 moles x $22.4 \mathrm{dm}^{3} / \mathrm{mol}$ results in $98,1 \mathrm{dm}^{3}$.

Total approximate consumption of hydrogen for the hydrotreatment of $1 \mathrm{~kg}$ of pyrolysis oil assuming complete hydrogenation of unsaturated bonds and complete hydrogenolysis of heteroorganic compounds and the basis for calculating $1 \mathrm{~kg}$ of oil from pyrolysis of rapeseed cake:

1. Total direct hydrogen consumption in the hydrotreatment process $1 \mathrm{~kg}$ of oil from pyrolysis oil cake should be $369.6 \mathrm{dm}^{3}+508 \mathrm{dm}^{3}+17.25 \mathrm{dm}^{3}+$ $98.1 \mathrm{dm}^{3}=$ about $993 \mathrm{dm}^{3}$ of hydrogen per $1 \mathrm{~kg}$ of oil.

2. As a result of complete removal of sulphur, oxygen and nitrogen from the product in simplified form, $0.82 \mathrm{~kg}$ of hydrotreated oil can be obtained from 1 $\mathrm{kg}$ of oil (the calculation does not include process losses)

3. The consumption of hydrogen per $1 \mathrm{~kg}$ of hydrotreated fuel will therefore be $993 \mathrm{dm}^{3} / \mathrm{kg} / 0.82$ $\mathrm{kg}=1211 \mathrm{dm}^{3}$.

4. Part of the hydrogen, ca. $20 \%$, will be lost along with the ammonia and hydrogen sulfide released, hence the total hydrogen consumption will be $1211 \mathrm{dm}^{3} \mathrm{x}$ $1.2=1453 \mathrm{dm}^{3}$. This part of hydrogen gas should be directed to the hydrogen recovery plant. Taking an approximate estimate of oil composition $1.5 \mathrm{~m}^{3}$ of hydrogen per $1 \mathrm{~kg}$ of oil after hydrotreatment, i.e. $1500 \mathrm{~m}^{3}$ per 1 ton of fuel.

The decisive factor in the hydrotreatment process is gas availability and the cost of purchasing or the production cost. The cost of hydrogen production is difficult to evaluate, its price depends on many factors including the raw material properties and price as well as the production method. The cheapest method so far seems to be hydrogen production by methane steam reforming (MSR).

Such deep hydrotreatment, i.e. complete hydrogenation of olefins and hydrogenolysis of sulphur, nitrogen and oxygen compounds to products in the form of ammonia, hydrogen sulfide and water is not possible because of hydrotreatment of oils from biomass pyrolysis is a difficult task. As it results from the composition of hydrotreatment products presented in Table 5, using fairly severe conditions of hydrotreatment at a low volume flow rate of raw material $\mathrm{LHSV}=0.5 \mathrm{~h}^{-1}$ (HR II), the product is not fully refined, there was the removal of $80 \%$ oxygen, $75 \%$ sulphur and hydrogenation $60 \%$ olefins was found. Hydrogenolysis of nitrogen compounds is the most difficult, the content of nitrogen in oil in the hydrotreatment process is reduced by only $29 \%$.

The effect of hydrotreating oil from pyrolysis was less effective using higher volume flow rates of raw material (HR I, LHSV $=2 h^{-1}$, Table 5). The properties of the obtained hydrotreatment products in both cases do not meet the expectations from the fuel quality requirement view, e.g. heating oil due to too high content of sulphur and nitrogen, resulting in the combustion process to excessive emission of sulphur and nitrogen oxides. The unsatisfactory degree of hydrotreatment is also evidenced by the fact that dark brown colour of raw pyrolytic oils changes during hydrorefining only partially to deep yellow.

The average, weighted hydrogen consumption in the hydrotreatment process HRII (Table 5), concerning 1 ton of the hydrotreatment products obtained in this process is as follows:

$0.6 \times 369.6 \mathrm{dm}^{3}+0.29 \times 508 \mathrm{dm}^{3}+0.75 \times 17.25 \mathrm{dm}^{3}$ $+0.6 \times 98.1 \mathrm{dm}^{3}=221.8+147.3+12.9+58.9=440.9 \mathrm{~m}^{3}$. To obtain 1 ton of the refined product from the pyrolysis of oil cake, approximately $660 \mathrm{~m}^{3}$ of hydrogen. This is

Table 5. Physicochemical properties of pyrolysis oil and products of its hydrorefining over $\mathrm{NiMo} / \mathrm{Al}_{2} \mathrm{O}_{3}$ catalyst.

\begin{tabular}{|c|c|c|c|}
\hline Properties & $\begin{array}{c}\text { Raw material, } \\
\text { rapeseed cake pyrolytic } \\
\text { bio-oil }\end{array}$ & $\begin{array}{c}\text { Product HR I } \\
\mathrm{T}=350^{\circ} \mathrm{C}, \mathrm{p}=3 \mathrm{MPa}, \\
\mathrm{LHSV}=2 \mathrm{~h}^{-1}\end{array}$ & $\begin{array}{c}\text { Product HR II } \\
\mathrm{T}=350^{\circ} \mathrm{C}, \mathrm{p}=3 \mathrm{MPa}, \\
\mathrm{LHSV}=0.5 \mathrm{~h}^{-1}\end{array}$ \\
\hline \multicolumn{4}{|c|}{ Elemental analysis, \%, daf } \\
\hline $\mathrm{C}$ & 71.50 & 74.90 & 79.80 \\
\hline $\mathrm{H}$ & 10.20 & 12.10 & 12.90 \\
\hline $\mathrm{N}$ & 7.05 & $6.42\left(0.09^{\mathrm{a}}\right)$ & $5.02\left(0.29^{\mathrm{a}}\right)$ \\
\hline $\mathrm{S}$ & 0.70 & $0.33\left(0.53^{\mathrm{a}}\right)$ & $0.18\left(0.75^{\mathrm{a}}\right)$ \\
\hline $\mathrm{O}$ & 10.55 & $6.25\left(0.41^{\mathrm{a}}\right)$ & $2.10\left(0.80^{\mathrm{a}}\right)$ \\
\hline Bromine number, $\mathrm{gBr}_{2} / 100 \mathrm{~g}$ & 79.70 & $41.4\left(0.48^{\mathrm{a}}\right)$ & $32.3\left(0.60^{\mathrm{a}}\right)$ \\
\hline Calorific value, $\mathrm{MJ} / \mathrm{kg}$ & 32.5 & 36.4 & 40.5 \\
\hline
\end{tabular}

a) hydrogenolysis degree of N, S and O-containing hetero compounds and hydrogenation of olefins 
a high cost of hydrogen, keeping in mind other significant costs that are difficult to determine, including:

- pyrolysis costs, plant depreciation, operating costs;

- costs of raw material for pyrolysis, i.e. in this case rapeseed cake;

- transport costs of the rapeseed cake to the pyrolysis and hydrotreatment plants.

The access to the hydrotreatment system and the hydrogen source is a particularly difficult problem. The production of oils from biomass pyrolysis is usually too low for the construction of a local hydrotreatment installation and hydrogen production plant to be economically justified. To obtain the right amount of hydrotreating raw material, it would be necessary to ensure deliveries from larger areas of the country. Of course, for smaller installations, there is the possibility of local hydrogen production by water electrolysis.

A better solution is to transport oils from the pyrolysis plant to the hydrotreatment plant at the nearest refinery. Biomass pyrolysis oil can then be refined together with other petroleum products. The disadvantage of this solution is the need to obtain the refinery's approval for the service, its cost and the cost of the transport from more distant parts of the country to the refinery.

Energy value of hydrogen used for hydrotreating of 1 ton of pyrolysis oil (for HRII, Table 5):

$120 \mathrm{MJ} / \mathrm{kg}$ x $660 \mathrm{Nm}^{3}$ x $0.09 \mathrm{~kg} / \mathrm{Nm}^{3}=7.128 \mathrm{GJ}$

Energy value consumption at full hydrotreatment: $7.128 \times 1500 / 660=16.2$ GJ

Energy value of heating oil produced $43.2 \mathrm{MJ} / \mathrm{kg}$, i.e. $43 \mathrm{GJ} / \mathrm{ton}$.

This means that large quantities of hydrogen should be used to obtain well-refined biofuels. Hydrogen calorific value constitutes about $30 \%$ of the calorific value of the fuel produced as a result of hydrotreatment. Thus, hydrogen being an excellent gas fuel, is used to produce fuels, such as bio-oils with much worse utility parameters. The detailed calculation of the energy costs of pyrolysis and hydrotreatment, the costs of use or construction of appropriate installations (pyrolysis and hydrotreatment) and their servicing as well as the logistics costs should lead to the conclusion that the production of bio-oils by biomass pyrolysis is not rationally justified.

\section{Conclusions}

Elemental analysis and ${ }^{1} \mathrm{H}$ NMR, ${ }^{13} \mathrm{C}$ NMR and IR spectroscopic methods were used to characterize slow pyrolysis bio-oils from three different feedstocks, including rapeseed, rapeseed cake and rapeseed meal.

Pyrolytic bio-oils contain a high quantity of nitrogen (2.9-8.2 wt. \% daf) and oxygen (4.7-10.5 wt. \% daf). Among examined bio-oils, bio-oil from rapeseed is characterized by the least oxygen and nitrogen content.
According to the results of elemental analysis, bromine number, acid hydroxide groups content and chemical structure examined bio-oils cannot be directly used as internal combustion fuels or fuel oils. It applies particularly to the bio-oils from rapeseed meal and rapeseed cake, which are characterized among others by high nitrogen and oxygen content and high content of unsaturated hydrocarbons.

The results of ${ }^{1} \mathrm{H}$ NMR and ${ }^{13} \mathrm{C}$ NMR analysis indicate that bio-oils obtained in the pyrolysis process are mixtures of alkanes and alkenes. The highest content of aliphatic carbon was observed in bio-oil from rapeseed $(74 \%)$, and the lowest in bio-oil from rapeseed meal (42.9\%). As a consequence of high aliphatics content, bio-oils from rapeseed and rapeseed cake are characterized by a high $\mathrm{H} / \mathrm{C}$ atomic ratio (1.71-1.74). Amongst the all above-mentioned chemical groups olefins and aromatics are the main compounds in bio-oil from rapeseed meal $(54.7 \%)$. The increase of unsaturated chemical compounds in the bio-oils structure was confirmed by bromine number increase along with the decrease of oil content in the raw material used for pyrolysis.

Pyrolysis derived bio-oils from rapeseed, rapeseed cake and rapeseed meal are treated as a potentially good intermediate for the production of liquid fuel or fuel oil components. Rapeseed grain seems to be too expensive and too valuable for the pyrolytic production of such bio-oils. Other bio-oils, liquid products of rapeseed crops pyrolysis e.g. from rapeseed cake are characterized by high nitrogen content (7.0 wt.\% daf.), oxygen content (10.5 wt \% daf.) and olefins content which complicates hydrorefining process and ammonia as hydrogenolysis product of nitrogen compounds negatively influence sulfided catalyst activity. It was shown that refining these fractions to a satisfactory level was a difficult task. All nitrogen and oxygencontaining compounds are very stable and their hydrogenolysis needs severe process parameters. The dark brown color of raw pyrolytic oils changes during hydrorefining only partially to deep yellow. These observations and physicochemical properties of the obtained hydrorefining products, which include still high nitrogen, oxygen and sulphur content and high bromine number indicate that the upgrading level of the product is unsatisfactory.

The production of good-quality bio-oils requires not only severe parameters of the hydrotreatment process but, as shown, the consumption of large amounts of hydrogen accounting for about $30 \%$ of the energy value of the produced biofuel. It is necessary to take into account other costs, costs of pyrolysis and biooil hydrotreatment, the costs of use or construction of appropriate installations (pyrolysis and hydrotreatment) and their servicing as well as the logistics costs.

Analysis of the hydrotreating effects of pyrolysis bio-oils, calculations of hydrogen consumption in the hydrotreatment process and other costs mentioned in this study gives grounds for an estimation that biomass 
pyrolysis as a method of producing liquid fuels should not be used as economically supported.

\section{Acknowledgements}

The authors would like to gratefully acknowledge to Mr. Paweł Dąbrowski from Wroclaw University of Science and Technology NMR Laboratory, for his support in NMR analysis.

\section{Conflict of Interest}

The authors declare no conflict of interest.

\section{References}

1. NUNES L.J.R., CAUSER T.P., CIOLKOSZ D. Biomass for energy: A review on supply chain management models. Renewable and Sustainable Energy Reviews, 120 (April 2019), 109658, 2020.

2. HANSEN S., MIRKOUEI A., DIAZ L.A. A comprehensive state-of-technology review for upgrading bio-oil to renewable or blended hydrocarbon fuels. Renewable and Sustainable Energy Reviews, 118 (June 2019), 109548, 2020.

3. WANG F., OUYANG D., ZHOU Z., PAGE S.J., LIU D., ZHAO X. Lignocellulosic biomass as sustainable feedstock and materials for power generation and energy storage. Journal of Energy Chemistry, 57, 247, 2021.

4. ELLISON C.R., HOFF R., MĂRCULESCU C., BOLDOR D. Investigation of microwave-assisted pyrolysis of biomass with char in a rectangular waveguide applicator with built-in phase-shifting. Applied Energy, 259 (September 2019), 2020.

5. LI S., CHEN X., LIU A., WANG L., YU G. Co-pyrolysis characteristic of biomass and bituminous coal. Bioresource Technology, 179, 414, 2015.

6. WANG J., LIU Q., ZHOU J., YU Z. Production of HighValue Chemicals by Biomass Pyrolysis with Metal Oxides and Zeolites. Waste and Biomass Valorization, (0123456789), 2020.V

7. FLACH B., LIEBERZ S., BOLLA S. EU-28. Biofuels Annual. EU Biofiels Annual 2019. USDA Foreign Agricultural Service. Global Agricultural Information Network. Report no. NL9022, 2019. Available online: https://apps.fas.usda.gov/newgainapi/api/report/download reportbyfilename?filename $=$ Biofuels $\% 20$ Annual_The $\% 20$ Hague_EU-28_7-15-2019.pdf

8. PALIZDAR A., SADRAMELI S.M. Catalytic upgrading of beech wood pyrolysis oil over iron- and zinc-promoted hierarchical MFI zeolites. Fuel, 264 (August 2019), 116813, 2020.

9. HASSAN N.S., JALIL A.A., HITAM C.N.C., VO D.V. N., NABGAN W. Biofuels and renewable chemicals production by catalytic pyrolysis of cellulose: a review. Environmental Chemistry Letters, 18 (5), 1625, 2020.

10. MULLEN C.A., STRAHAN G.D., BOATENG A.A. Characterization of Various Fast-Pyrolysis Bio-Oils by NMR Spectroscopy $\uparrow$. Energy Fuels, 23 (5), 2707, 2009.

11. THANGALAZHY-GOPAKUMAR S., ADHIKARI S., GUPTA R.B., FERNANDO S.D. Influence of Pyrolysis
Operating Conditions on Bio-Oil Components: A Microscale Study in a Pyroprobe. Energy Fuels, 25 (3), 1191, 2011.

12. HOSSAIN A.K., DAVIES P.A. Pyrolysis liquids and gases as alternative fuels in internal combustion engines - A review. Renewable and Sustainable Energy Reviews, 21, 165,2013

13. LEAL MENDES F., TEIXEIRA DA SILVA V., EDRAL PACHECO M., DE REZENDE PINHO A., ASSUMPÇÃO HENRIQUES C. Hydrotreating of fast pyrolysis oil: A comparison of carbons and carbon-covered alumina as supports for Ni2P. Fuel, 264 (June 2019), 116764, 2020.

DASARI K.K., GUMTAPURE V., DUTTA S. Upgrading of coconut shell-derived pyrolytic bio-oil by thermal and catalytic deoxygenation. Energy Sources, Part A: Recovery, Utilization, and Environmental Effects, 1, 2020.

14. LY H.V., KIM J., HWANG H.T., CHOI J.H., WOO H.C., KIM S.S. Catalytic hydrodeoxygenation of fast pyrolysis bio-oil from saccharina Japonica alga for bio-oil upgrading. Catalysts, 9 (12), 2019.

15. MULLEN C.A., BOATENG A.A. Mild hydrotreating of bio-oils with varying oxygen content produced via catalytic fast pyrolysis. Fuel, 245 (February), 360, 2019.

16. YAN P., DREWERY M., MENSAH J., MACKIE J.C., KENNEDY E., STOCKENHUBER M. Study on Catalyst Deactivation During the Hydrodeoxygenation of Model Compounds. Topics in Catalysis, 63 (9-10), 778, 2020.

17. GHOLIZADEH M., GUNAWAN R., HU X., KADARWATI S., WESTERHOF R., CHAIWAT W., ... LI C.Z. Importance of hydrogen and bio-oil inlet temperature during the hydrotreatment of bio-oil. Fuel Processing Technology, 150, 132, 2016.

18. GARCIA-PEREZ M., SHEN J., WANG X.S., LI C.-Z. Production and fuel properties of fast pyrolysis oil/biodiesel blends. Fuel Processing Technology, 91 (3), 296, 2010.

19. SHAHZEB KHAN M., RAFIQ M., SOOKRAH V., THOMSON M.J. Effect of Dewatering Wood-Derived Fast Pyrolysis Oil on Its Fuel Properties for Power Generation. Energy Fuels, 33 (12), 12403, 2019.

20. KUMAR R., STREZOV V. Thermochemical production of bio-oil: A review of downstream processing technologies for bio-oil upgrading, production of hydrogen and high value-added products. Renewable and Sustainable Energy Reviews, 135 (August 2020), 110152, 2021.

21. DAVID E., KOPAC J. Pyrolysis of rapeseed oil cake in a fixed bed reactor to produce bio-oil. Journal of Analytical and Applied Pyrolysis, 134, 495, 2018.

22. MIKULSKI M., AMBROSEWICZ-WALACIK M., DUDA K., HUNICZ J. Performance and emission characterization of a common-rail compression-ignition engine fuelled with ternary mixtures of rapeseed oil, pyrolytic oil and diesel. Renewable Energy, 148, 739, 2020.

23. KUMAR P., SRIVASTAVA V.C., JHA M.K. Jatropha curcas phytotomy and applications: Development as a potential biofuel plant through biotechnological advancements. Renewable and Sustainable Energy Reviews, 59, 818, 2016.

24. ŁOPUSIEWICZ Ł., DROZŁOWSKA E., TARNOWIECKA-KUCA A., BARTKOWIAK A., MAZURKIEWICZ-ZAPAŁOWICZ K., SALACHNA P. Biotransformation of flaxseed oil cake into bioactive camembert-analogue using lactic acid bacteria, penicillium camemberti and geotrichum candidum. Microorganisms, 8 (9), 1, 2020. 
25. PSTROWSKA K., WALENDZIEWSKI J., ŁUŻNY R., STOLARSKI M. Hydroprocessing of rapeseed pyrolysis bio-oil over $\mathrm{NiMo} / \mathrm{Al}_{2} \mathrm{O}_{3}$ catalyst. Catalysis Today, 223, 54, 2014.

26. SURYGAŁA J., ŚLIWKA E. Oznaczanie kwaśnych grup hydroksylowych $\mathrm{w}$ cieczach węglowych metodą miareczkowania termometrycznego. Chemia Analityczna, 36, 933, 1991.

27. SILVERSTEIN R.M., WEBSTER FX K.D. Spectrometric identification of organic compounds ( $7^{\text {th }}$ Editio.). John Wiley\&Sons Inc, 2005.
28. SANNA A., OGBUNEKE K., ANDRÉSEN J.M. Bio-coke from upgrading of pyrolysis bio-oil for co-firing. Fuel, $\mathbf{8 8}$ (12), 2340, 2009.

29. SETIABUDI H.D., AZIZ M.A.A., ABDULLAH S., TEH L.P., JUSOH R. Hydrogen production from catalytic steam reforming of biomass pyrolysis oil or bio-oil derivatives: A review. International Journal of Hydrogen Energy, 45 (36), 18376, 2020. 